\title{
Evaluation of pulmonary dysfunctions and acid-base imbalances induced by Chlamydia psittaci in a bovine model of respiratory infection
}

\author{
Carola Ostermann ${ }^{1 \dagger}$, Susanna Linde ${ }^{1 \dagger}$, Christiane Siegling-Vlitakis ${ }^{2}$ and Petra Reinhold ${ }^{1 *}$
}

\begin{abstract}
Background: Chlamydia psittaci $(C p)$ is a respiratory pathogen capable of inducing acute pulmonary zoonotic disease (psittacosis) or persistent infection. To elucidate the pathogenesis of this infection, a translational large animal model was recently introduced by our group. This study aims at quantifying and differentiating pulmonary dysfunction and acid-base imbalances induced by $C p$.

Methods: Forty-two calves were grouped in (i) animals inoculated with $C p(n=21)$ and (ii) controls shaminoculated with uninfected cell culture $(n=21)$. For pulmonary function testing, impulse oscillometry, capnography, and FRC (functional residual capacity) measurement were applied to spontaneously breathing animals. Variables of acid-base status were assessed in venous blood using both (i) traditional Henderson-Hasselbalch and (ii) strong ion approach.

Results: Both obstructive and restrictive pulmonary disorders were induced in calves experimentally inoculated with Cp. Although disorders in respiratory mechanics lasted for 8-11 days, the pattern of spontaneous breathing was mainly altered in the period of acute illness (until 4 days post inoculation, dpi). Expiration was more impaired than inspiration, resulting in elevated FRC. Ventilation was characterised by a reduction in tidal volume (-25\%) combined with an increased percentage of dead space volume and a significant reduction of alveolar volume by $10 \%$. Minute ventilation increased significantly $(+50 \%)$ due to a compensatory doubling of respiratory rate. Hyperventilatory hypocapnia at 2-3 dpi resulted in slightly increased blood pH at 2 dpi. However, the acid-base equilibrium was additionally influenced by metabolic components, i.e. the systemic inflammatory response, all of which were detected with help of the strong ion theory. Decreased concentrations of albumin (2-10 dpi), a negative acute-phase marker, resulted in a decrease in the sum of non-volatile weak acids $\left(A_{\text {tot }}\right)$, revealing an alkalotic effect. This was counterbalanced by acidic effects of decreased strong ion difference (SID), mediated by the interplay between hypochloraemia (alkalotic effect) and hyponatraemia (acidic effect).
\end{abstract}

Conclusions: This bovine model was found to be suitable for studying pathophysiology of respiratory Cp infection and may help elucidating functional host-pathogen interactions in the mammalian lung.

Keywords: Acid-base status, Animal model, Chlamydia psittaci, Pulmonary function

\footnotetext{
* Correspondence: petra.reinhold@fli.bund.de

${ }^{\dagger}$ Equal contributors

'Institute of Molecular Pathogenesis at 'Friedrich-Loeffler-Institut' (Federal Research Institute for Animal Health), Naumburger Str. 96a, 07743 Jena,

Germany

Full list of author information is available at the end of the article
} 


\section{Background}

Chlamydiae include important respiratory pathogens. In humans, infections with Chlamydia (C.) psittaci are typical examples of pulmonary zoonotic diseases, historically known as psittacosis (parrot fever) or ornithosis (transmitted from poultry). Taking into consideration that chlamydial infections are frequently present in cattle herds [1], the bovine species was also proven to be a natural host for C. psittaci [2-6]. Although a bovine model of experimentally induced C. psittaci infection was recently introduced by our group [7] we are still far from fully understanding the pathogenesis and consequences of C. psittaci infections.

However, addressing open questions by using a large animal model can offer greater clinical translational potential [8] and benefits both, human and veterinary medicine [9]. In this particular model, the respiratory tract as the target organ was chosen because there is still a lack of knowledge regarding the pathophysiology of pulmonary disorders induced by $C$. psittaci. With respect to the clinical outcome, respiratory chlamydial infections are known to be highly variable. Human and avian C. psittaci infections may range from clinically silence to acute respiratory and systemic illness. In human medicine, acute 'atypical pneumonia' is a well-known phenomenon in patients that acquired psittacosis due to zoonotic transmission [10-12]. Persistent infection with C. psittaci, however, was identified in humans with pulmonary emphysema and/or chronic obstructive pulmonary disease (COPD) as well as in horses with chronic recurrent airway obstruction [13,14] suggesting a pathogenetic link between chronic pulmonary inflammation and persistent infection with chlamydiae. Similar observations were reported for the bovine lung. While an acute outbreak of upper respiratory tract disease in calves was attributed to Chlamydia [3], chronic recurrent chlamydial infections in calves remained clinically inconspicuous but were associated with persistent peripheral airway obstruction and chronic pulmonary inflammation [15].

Our defined respiratory model of C. psittaci infection in calves offers the possibility to study cause-effect relationships under biologically relevant conditions, i.e. between a pathogen with a clear affinity to the respiratory system and a natural host. This particular study was allocated (i) to identify and to quantify acute respiratory dysfunction induced by $C$. psittaci in a mammalian lung comparable to the human lung in terms of volumes and airflows. To assess lung function parameters typically measured in human medicine, effort-independent and non-invasive pulmonary function techniques common in human pulmonology were applied to conscious and spontaneously breathing calves. (ii) In order to evaluate systemic consequences of pulmonary dysfunctions, acid-base imbalances were quantified and differentiated by assessing metabolites and electrolytes taking both the traditional Henderson-Hasselbalch approach and the new strong ion models $[16,17]$ into account.

The results of this study provide new information regarding the pathophysiology of acute respiratory infection caused by $C$. psittaci with relevance for both veterinary and human medicine taking the ONE HEALTH concept into account.

\section{Methods}

\section{Legal conformity and ethics statement}

This study was carried out in strict accordance with European and National Law for the Care and Use of Animals. The protocol was approved by the Committee on the Ethics of Animal Experiments and the Protection of Animals of the State of Thuringia, Germany (Permit Number: 04-002/07). All experiments were done in a containment of biosafety level 2 under supervision of the authorised institutional Agent for Animal Protection. Bronchoscopy to inoculate the pathogen was strictly performed under general anaesthesia. During the entire study, every effort was made to minimise suffering.

\section{Animals}

In this prospective and controlled study, 42 conventionally raised calves (Holstein-Friesian breed, male) were included. Animals originated from one farm where each individual calf was fed with maternal colostrum for at least three consecutive meals after birth. In the subsequent period, calves received mixed colostrum until they were purchased at the age of 14 to 28 days weighing between 42.2 and $71.2 \mathrm{~kg}(56.3 \pm 6.8 \mathrm{~kg}$; mean $\pm \mathrm{SD})$. The herd of origin was without any history of Chlamydiaassociated health problems (regularly checked by the National Reference Laboratory for Psittacosis). In the institute calves were reared under standardised conditions (room climate: $18-20^{\circ} \mathrm{C}$, rel. humidity: 60-65\%) and in accordance with international guidelines for animal welfare. Throughout the entire study, nutrition included commercial whey-based milk replacers and coarse meal. Water and hay were supplied ad libitum. None of the given feed contained antibiotics.

\section{Study design}

At the age of 42-64 days, 21 calves weighing $73.9 \pm 7.4 \mathrm{~kg}$ were inoculated with $10^{8}$ inclusion forming units (ifu) of a bovine $C$. psittaci strain (DC 15) per calf, whereas another 21 calves (body weight: $69.3 \pm 8.3 \mathrm{~kg}$; mean $\pm \mathrm{SD}$ ) served as controls. Preparation of the challenge strain, procedure of intrabronchial inoculation using a flexible video-bronchoscope and scheme of inoculation at $8 \mathrm{de}$ fined localisations in the lung have been described elsewhere [7]. Controls were inoculated with uninfected 
Buffalo Green Monkey Kidney cell culture suspended in $6 \mathrm{~mL}$ stabilising medium SPGA (containing saccharose, phosphatile substances, glucose and bovine albumin; [18]) using the same methodology.

As illustrated in Table 1, pulmonary function tests (PFT) were performed in 18 C. psittaci-infected and in 18 sham-inoculated calves from 7 days ante inoculation (a.i.) up to 14 days post inoculation (dpi). Body weight (b.w.) was measured individually prior to each lung function test. Prior morning feeding blood samples were collected from the jugular vein starting 1 hour a.i. up to 14 dpi (Table 1). After blood sampling and PFT per day, three calves per group were sacrificed 2, 4, 7, 10, and 14 dpi. Consequently, the number of calves per group decreased continuously from $n=21$ at the beginnig of the study to $n=6$ at the end of the study ( $14 \mathrm{dpi}$ ).

\section{Protocol of pulmonary function testing}

All PFT measurements were performed in conscious calves breathing spontaneously through a tightly fitting facemask (dead space of facemask: $<100 \mathrm{~mL}$ ), and in a room with controlled ambient conditions $\left(18-20^{\circ} \mathrm{C}\right.$, rel. humidity: 60-65\%). After an adaptation period of approximately $5 \mathrm{~min}$, three non-invasive lung function techniques (all JAEGER, CareFusion) were applied consecutively to each animal per time point: (1) impulse oscillometry system to assess respiratory mechanics, (2) volumetric capnography to measure the concentration of exhaled $\mathrm{CO}_{2}$ against exhaled volume, and (3) re-breathing system to assess FRC (functional residual capacity). All systems were originally produced for human medicine and have been successfully applied to calves previously [19-22]. In each system, a Lilly-type pneumotachograph (mesh resistance: $36 \mathrm{~Pa} /(\mathrm{L} / \mathrm{s})$ ) was used for continuous measurement of airflow (V').

\section{Impulse oscillometry}

Complex respiratory impedance, consisting of both respiratory resistance (Rrs) and respiratory reactance (Xrs), was analysed in the frequency range $3 \mathrm{~Hz}-15 \mathrm{~Hz}$ as described elsewhere $[15,22,23]$. In addition, proximal airway resistance (Rprox) and distal airway resistance
(Rdist) were calculated [15,21]. Three impulse oscillometry measurements were performed per calf and time point as described by Jaeger et al. (2007) [15]. Duration of one measurement was 60 seconds with 3 test impulses per second (sec), and 32 sampling points after each impulse with a period between two sampling points of $5 \mathrm{~ms}$. Results of three measurements per animal and time point were averaged and these average values were used for further statistical analysis.

\section{Volumetric capnography}

Volumetric capnography is the projection of expired $\mathrm{CO}_{2}$ versus expired volume. In a breath-by-breath analysis, 10 exhaled $\mathrm{CO}_{2}$ curves were registered per calf and time point in triplicate. Dead space volume and end-tidal $\mathrm{CO}_{2}$ were calculated for each breath as shown in Figure 1. Results of all 30 exhaled $\mathrm{CO}_{2}$ concentration curves per individual measurement were averaged for further statistical analyses.

\section{Re-breathing method}

FRC of the lung was measured by the multiple breath Helium-dilution technique (wash-in), using Helium (He) as test component of the inspired gaseous mixture (inspiratory concentrations: $7-10 \% \mathrm{He}, 35 \%$ oxygen, rest nitrogen). The volume of the reservoir (re-breathing) bag was filled with $9 \mathrm{~L}$ of the test gas, expired $\mathrm{CO}_{2}$ was absorbed and $\mathrm{O}_{2}$ was added when the bag volume decreased. Re-breathing time to perform the test was 2 minutes $\pm 38 \mathrm{sec}$ (mean $\pm \mathrm{SD}$ ).

All PFT parameters were calculated automatically using the software included in the three systems. For further analysis, the following variables of pulmonary function were taken into account: - complex respiratory impedance in the frequency range $3 \mathrm{~Hz}-15 \mathrm{~Hz}$; expressed as respiratory resistance (Rrs) and respiratory reactance (Xrs); each separated for inspiration and expiration, - proximal and distal airway resistance (Rprox, Rdist), - respiratory rate (RR), - time of inspiration and time of expiration (Tin, Tex), - tidal volume (Vt), - volume of minute ventilation $(\mathrm{Vmin}=\mathrm{Vt}$ " RR), - tidal volume in relation to body weight (Vt/kg), - airflow (V') during in- and expiration (V'in, V'ex), - ratio between dead space volume and tidal volume $(\mathrm{Vd} / \mathrm{Vt})$, - functional residual capacity of the lung (FRC).

Table 1 Study design

\begin{tabular}{|c|c|c|c|c|c|c|c|c|c|c|c|c|c|}
\hline & Animals & -7 & -4 & -1 & +1 & +2 & +3 & +4 & +7 & +8 & +10 & +11 & +14 \\
\hline & & d a.i. & d a.i. & h a.i. & dpi & dpi & dpi & dpi & dpi & dpi & dpi & dpi & dpi \\
\hline \multirow[t]{2}{*}{ PFT } & C. psittaci & $\mathrm{n}=18$ & $\mathrm{n}=18$ & & & & $\mathrm{n}=18$ & $n=15$ & $\mathrm{n}=12$ & $n=9$ & $n=9$ & $n=6$ & $n=6$ \\
\hline & Controls & $\mathrm{n}=18$ & $\mathrm{n}=18$ & & & & $\mathrm{n}=18$ & $n=15$ & $\mathrm{n}=12$ & $n=9$ & $n=9$ & $n=6$ & $n=6$ \\
\hline \multirow[t]{2}{*}{ Blood } & C. psittaci & & & $n=21$ & $n=21$ & $n=21$ & $n=18$ & $n=15$ & $n=12$ & & $n=9$ & & $n=6$ \\
\hline & Controls & & & $n=21$ & $n=21$ & $n=21$ & $n=18$ & $n=15$ & $n=12$ & & $n=9$ & & $n=6$ \\
\hline
\end{tabular}

$\mathrm{d}$ a.i./h a.i., day/hour ante inoculation (baseline); dpi, day post inoculation; PFT, pulmonary function testing. 


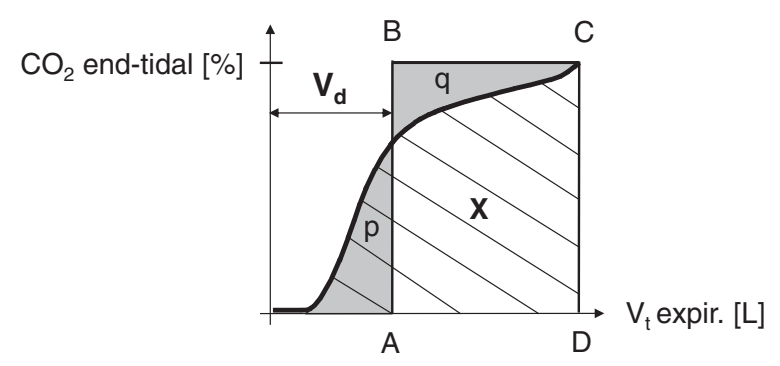

Figure 1 Evaluation of dead space volume (Vd) and end-tidal $\mathrm{CO}_{2}$ concentration using volumetric capnography. The rectangle $\mathrm{ABCD}$ represents the same area as the $\mathrm{CO}_{2}$-volume-area under the capnographic curve $(\mathrm{X})$ while $\mathbf{B C}$ represents a constant $\mathrm{CO}_{2}$ concentration that equals to end-tidal $\mathrm{CO}_{2}$. In this case, areas $p$ and $q$ are of the same size, and $V d$ according to Bohr represents the volume without $\mathrm{CO}_{2}$

\section{Protocol of acid-base assessment}

Jugular venous blood was collected (i) anaerobically in $2 \mathrm{~mL}$ polypropylene syringes with lyophilised electrolytebalanced heparin (PICO 50, Radiometer Copenhagen) for immediate analysis and (ii) in $9.0 \mathrm{~mL}$ syringes (S-Monovette, Sarstedt AG \& Co) for serum production.

\section{Analysis of jugular venous blood}

Heparinised blood samples were transported to the laboratory at room temperature and analysed within $10 \mathrm{~min}$ of collection using a combined blood-gas- and electrolyteanalyser (ABL 725, Radiometer), working with manufacturer's standard electrodes. The following factors were measured in the venous (v) blood: $\mathrm{pH}(\mathrm{v})$, partial pressure of $\mathrm{CO}_{2}\left(\mathrm{pCO}_{2}(\mathrm{v})\right)$, and the plasma concentrations of sodium $\left(\mathrm{cNa}^{+}\right)$, potassium $\left(\mathrm{cK}^{+}\right)$, calcium $\left(\mathrm{cCa}^{2+}\right)$ and chloride $\left(\mathrm{cCl}^{-}\right)$by ion-selective potentiometry. Plasma concentrations of glucose (cGlucose) and L-lactate (cLlactate) were measured in the same equipment using enzymatic electrodes.

\section{Serum biochemical analysis}

Serum was harvested by centrifugation (3120 g for $15 \mathrm{~min}$ at $15^{\circ} \mathrm{C}$ ) and stored at $-20^{\circ} \mathrm{C}$ until analysed. Serum concentrations of total protein (biuret method) and inorganic phosphate (ammonium-molybdate) were measured spectrophotometrically (Cobas 6000, Roche/Hitachi). Capillary electrophoresis was performed to determine concentrations of albumin and globulin, as well as the globulin spectra ('Capillarys2', Sebia).

\section{Calculated acid-base variables}

The following variables were calculated using proprietary equations included in the software of the bloodgas- and electrolyte-analyser: blood $\mathrm{pH}$ and $\mathrm{pCO}_{2}(\mathrm{v})$, each corrected for the actual body temperature (BT) of the animal as measured rectally via digital thermometer before each blood collection ( $\mathrm{pH}$ вт, $\mathrm{pCO}_{2}(\mathrm{v})_{\text {вт }}$ ) and traditional variables of acid-base balance, i.e. bicarbonate $\left(\mathrm{cHCO}_{3}^{-}\right)$, standard bicarbonate $\left(\mathrm{cHCO}_{3}^{-}(\mathrm{st})\right)$, actual base excess (cBase), and standard base excess (cBase (Ecf)). The Henderson-Hasselbalch approach quantifies the unmeasured anion concentration by calculating the anion gap (AG) as follows [24-26]:

$$
A G=\left(c N a^{+}+c K^{+}\right)-\left(c \mathrm{Cl}^{-}+c \mathrm{HCO}_{3}{ }^{-}\right)
$$

The strong ion model [16] simplified by Constable [17] provides a novel insight into the pathophysiology of mixed acid-base disorders. This approach is based on the assumption that plasma $\mathrm{pH}$ is a dependent variable and as such its value is determined by three independent factors: $\mathrm{pCO}_{2}$, the strong ion difference (SID), and the sum of non-volatile weak acids $\left(\mathrm{A}_{\mathrm{tot}}\right)$ [27]. SID is the difference between the total sum of all strong cation concentrations and the sum of all strong anion concentrations. Strong ions are those that dissociate completely at physiologic $\mathrm{pH}$, existing either as strong cations $\left(\mathrm{Na}^{+}, \mathrm{K}^{+}, \mathrm{Ca}^{2+}\right.$, $\mathrm{Mg}^{2+}$ ) or strong anions (principally $\mathrm{Cl}^{-}$and L-lactate). The most important measured strong ions are $\mathrm{Na}^{+}, \mathrm{K}^{+}$and $\mathrm{Cl}^{-}$, calculated in $\mathrm{SIDm}_{3}[28,29]$.

$$
\operatorname{SIDm}_{3}[\mathrm{mmol} / L]=c N a^{+}+c K^{+}-c C l^{-a}
$$

All other electrolytes (measurable or unmeasurable) are involved in the strong ion gap (SIG), the difference between remaining unmeasured cations $\left(\mathrm{cUC}=\mathrm{Ca}^{2+}, \mathrm{Mg}^{2+}\right.$, and in very low amounts - and therefore negligible - micronutrients e.g. $\left.\mathrm{Cu}^{2+}, \mathrm{Fe}^{2+}, \mathrm{Fe}^{3+}, \mathrm{Zn}^{2+}, \mathrm{Co}^{2+}, \mathrm{Mn}^{2+}\right)$ and unmeasured anions (cUA $=\mathrm{SO}_{4}^{2-}$, lactate ${ }^{-}$, beta-hydroxybutyric acid ${ }^{-}$, acetoacetic acid $\left.^{-}\right)$[30].

$$
S I G=c U C-c U A
$$

Re-arranging gives:

$$
\begin{aligned}
& S I D=S I D m_{3}+S I G \text { or } \\
& S I D=\left(c N a^{+}+c K^{+}+c U C\right)-\left(c C l^{-}+c U A\right)
\end{aligned}
$$

The SID represents the net charge which must be balanced by charges on the weak acids in the solution for electrical neutrality to be maintained [17]. Acid total $\left(\mathrm{A}_{\text {tot }}\right)$ represents the total amount of non-volatile weak acid present in the system. The law of conservation of mass means that the total amount of $\mathrm{A}_{\text {tot }}$ in the system must be constant [31]. In plasma, the major non-volatile weak acids present are plasma proteins and phosphates $[32,33]$. In calves, however, the albumin concentration (cAlbumin) is most important and can be used alone as an estimate of $\mathrm{A}_{\text {tot }}$ in plasma, the results of which were used to calculate and prepare a gamblegram [34]. $A_{\text {tot }}$ and SIG were calculated from both total protein concentration (cProtein total) and cAlbumin and temperature 
corrected blood $\mathrm{pH}$ using the following equations and $\mathrm{pK}_{\mathrm{a}}$ data for calves $[25,26,28]$ :

$$
\begin{aligned}
& A_{\text {tot }(\text { Alb })}[\mathrm{mmol} / \mathrm{L}]=0.622 \times \text { cAlbumin }[g / L] \\
& A_{\text {tot }(\text { Prt })}[\mathrm{mmol} / L]=0.343 \times \text { cProtein total }[g / L] \\
& S I G=A_{\text {tot }} /\left(1+10^{(p K a-p H)}\right)-A G
\end{aligned}
$$

with $\mathrm{pK}_{\mathrm{a}}=7.08\left[\mathrm{~K}_{\mathrm{a}}=(0.84 \pm 0.41) \times 10^{-7}\right]$.

$$
\begin{aligned}
\operatorname{SIG}_{(A l b)}[\mathrm{mmol} / L]= & \text { cAlbumin }[g / L] \\
& \times\left(0,622 /\left(1+10^{(7,08-p H)}\right)-A G\right.
\end{aligned}
$$

$$
\begin{aligned}
\operatorname{SIG}_{(\text {Prt })}[\mathrm{mmol} / L]= & \text { cProtein total }[\mathrm{g} / L] \\
& \times\left(0,343 /\left(1+10^{(7,08-p H)}\right)-A G\right.
\end{aligned}
$$

\section{Statistical methods}

Normally distributed data are presented as mean and standard deviation (SD) while data with unknown or non-normal distribution are given as median and range. The analysis of lung function data was performed using PASW (Predictive Analyse Software) Statistics 17.0 (IBM Corporation) and StatgraphicsPlus 4.0 (StatPoint Technologies, Inc.). To compare multiple data with normal distribution, multifactorial analysis of variance (ANOVA) was used with Bonferroni's multiple comparison procedure as post hoc test. To compare two unpaired samples, i.e. differences between two groups at one time point, the unpaired $t$-test was used for normally distributed data (comparison of means) while the Mann-WhitneyWilcoxon $W$ test was used for data with unknown or non-normal distribution (comparison of medians).

For analysis of acid-base variables, Matlab (Matlab R2007a, Version 7.4.0.287; The MathWorks, Inc.) was used. Significant changes within each group compared to baseline data were assessed by Wilcoxon signed rank test, while Mann-Whitney-Wilcoxon $W$ test was used to identify significant differences between groups at a given time point $[35,36]$. Since the given $\mathrm{p}$ are equal or less than 0.05 , there is a statistically significant difference at the $95.0 \%$ confidence level. All confidence levels (p) are given with the results.

\section{Results}

\section{Respiratory mechanics}

Before challenge, complex respiratory impedance assessed by impulse oscillometry was comparable between groups and reproducible within each group (Figure 2; baseline data). After inoculation of C. psittaci, Xrs - representing the elastic properties of the lung - decreased significantly at all frequencies $(3-15 \mathrm{~Hz})$ compared to control calves. Coevally, respiratory resistance at low frequencies (Rrs $\leq 5 \mathrm{~Hz}$ ) increased significantly. This effect was stronger during expiration (Figure 2) than inspiration (data not shown). Figure 2 illustrates frequency-dependent courses of respiratory impedance assessed during expiration at selected time points indicating that significant differences in Xrs between groups lasted for at least 11 dpi. Numeric data (given in Table 2 for selected time points corresponding to Figure 2) and within-group analysis over time revealed a continuous growth-related increase in Xrs within the observation period of 21 days in controls that was clearly absent in calves exposed to C. psittaci. Instead, Xrs decreased significantly 3 dpi compared to intra-group baseline data before inoculation of C. psittaci (Table 2).

Proximal and distal airway resistances (Rprox, Rdist) are given in Figure 3A-B. Calves exposed to C. psittaci showed significantly elevated Rprox and Rdist data compared to controls as well as compared to intra-individual baseline data. Interestingly, the increase in Rdist was larger (146\%; mean of intra-subject difference between baseline a.i. and 3 dpi) compared to the increase in Rprox (116\%), but duration of significantly-elevated airway resistance lasted longer in proximal airways (until $8 \mathrm{dpi}$ ) compared to distal airways (4 dpi).

\section{Respiratory pattern}

The pattern of spontaneous breathing was characterised by the variables given in Figure 4. In controls, tidal volume (Vt) increased continuously due to growth over time. Averaged respiratory rate (RR) was 28 breathing cycles per minute and did not change during the study. Thus, minute ventilation (Vmin) increased slightly (but not significantly) from $16.5 \mathrm{~L}$ (mean -7 days) to $19.4 \mathrm{~L}$ (mean $14 \mathrm{dpi}$ ). In calves exposed to C. psittaci, significant alterations in the respiratory pattern were seen 3-4 dpi compared to baseline data, characterised by a reduction of Vt by $25 \%$ and a doubling of RR. Consequently, Vmin increased to about 150\% of baseline. These changes were reversed by $10 \mathrm{dpi}$ and, compared to intra-group data before challenge, Vt was significantly increased while $R R$ was significantly decreased.

To eliminate any influence of growth from volumes of respiration, Vt was additionally calculated per $\mathrm{kg}$ b.w. (Figure 5A). In calves challenged with chlamydiae, minima of 6.9 and $6.7 \mathrm{~mL} / \mathrm{kg}$ (means) were measured at 3 and $4 \mathrm{dpi}$, while averaged Vt per $\mathrm{kg}$ b.w. ranged between $8.7 \mathrm{~mL} / \mathrm{kg}$ and $10.1 \mathrm{~mL} / \mathrm{kg}$ in controls and in challenged calves at other time points.

With doubling of RR in C. psittaci-exposed calves, time of inspiration (Tin) and time of expiration (Tex) were significantly shorter compared to baseline data before challenge (Tin: $0.44 \mathrm{sec} 3 \mathrm{dpi}$ compared to $1.0 \mathrm{sec}$ at baseline; Tex: $0.56 \mathrm{sec} 3 \mathrm{dpi}$ compared to $1.2 \mathrm{sec}$ at baseline; means). 

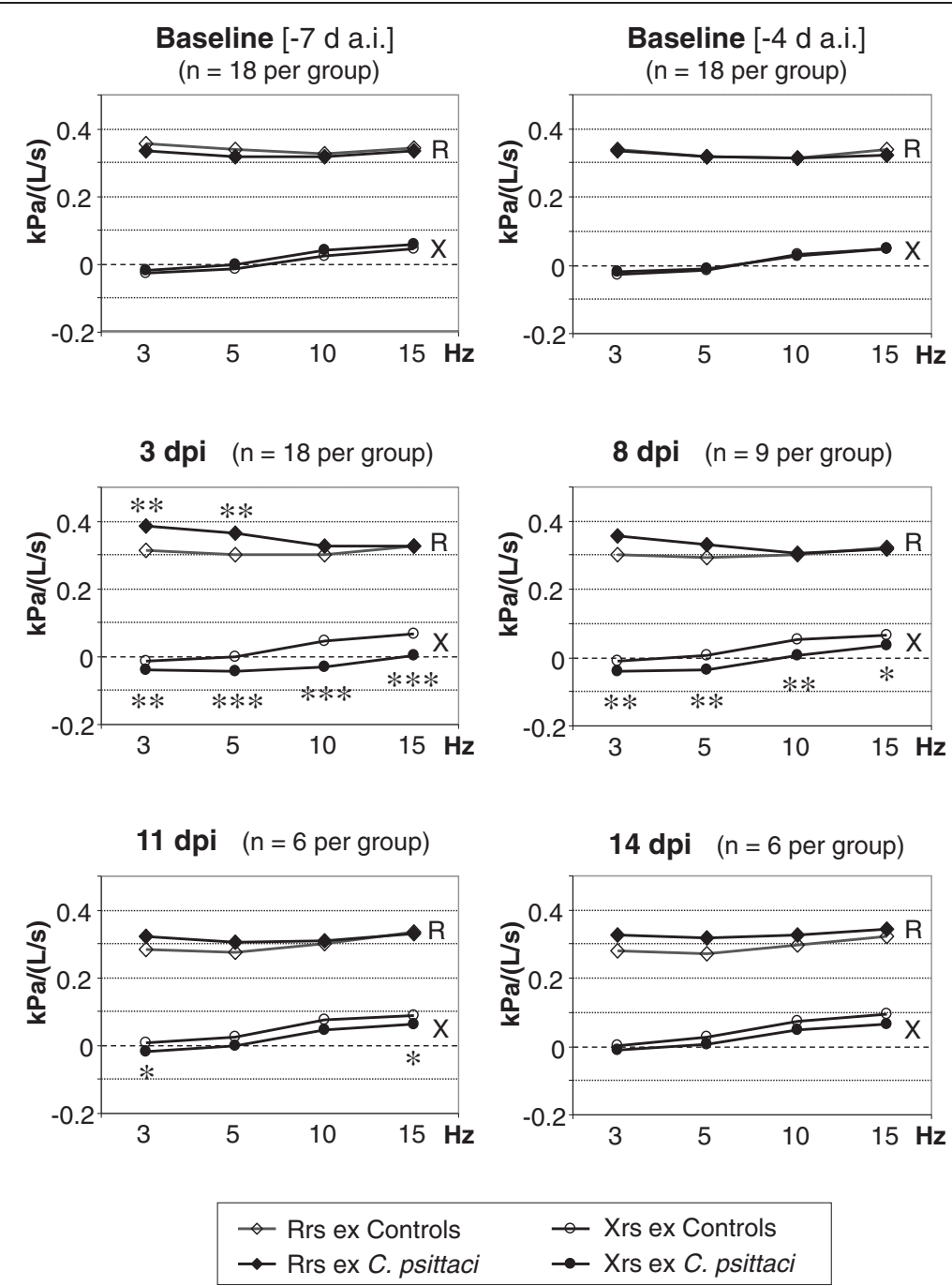

Figure 2 Respiratory impedance during expiration. Complex respiratory impedance during expiration is expressed as resistance (R) and reactance $(X)$. $d$ a.i., days after inoculation; dpi, days post inoculation; Rrs ex, respiratory resistance during expiration; Xrs ex, respiratory reactance during expiration. Open symbols: control calves. Filled symbols: calves inoculated with C. psittaci. Data are expressed as means per group. Significant differences between groups are indicated by ${ }^{*}(p<0.05),{ }^{* *}(p<0.01)$, or ${ }^{* *}(p<0.001)$ [unpaired $t$-test]. For reasons of visual clarity, data are expressed as means per group only. Numeric data presenting standard deviation and results of within-group comparison in addition are given in Table 2.

The mean ratio Tex:Tin, however, ranged within each group between 1.2 and 1.3 without changing significantly in any group at any time point (data not shown in detail).

Airflows assessed during inspiration and expiration (V'in, V'ex) revealed that mean inspiratory flow was physiologically higher $(0.8 \mathrm{~L} / \mathrm{s})$ compared to expiratory flow $(0.6 \mathrm{~L} / \mathrm{s})$ at baseline in both groups. Due to inoculation of chlamydiae, increases in airflows at time points $3 \mathrm{dpi}$ and $4 \mathrm{dpi}$ were comparable during in- and expiration (about $170 \%$ at 3 dpi and $140 \%$ at 4 dpi compared to baseline data). Data are only depicted for V'in (Figure 5B).

\section{Alveolar ventilation}

The mean ratio between dead space volume and tidal volume per breath (Vd:Vt, Figure 6A) was about 0.54 in controls as well as in calves before challenge with chlamydiae. Three and $4 \mathrm{dpi}$ of $C$. psittaci, the percentage of $\mathrm{Vd}$ per breath increased to $64 \%(\mathrm{Vd}: \mathrm{Vt}=0.64)$ in average indicating that alveolar volume per breath was reduced by about $10 \%$. FRC (i.e. the volume present in the lung at end of spontaneous expiration) was significantly increased by about $500 \mathrm{~mL}$ in the C. psittaci group. While FRC was $3.0 \mathrm{~L}(40.5 \mathrm{~mL} / \mathrm{kg}$ b.w.) at baseline, it was elevated to $3.5 \mathrm{~L}$ ( $45.7 \mathrm{~mL} / \mathrm{kg}$ b.w.) $3 \mathrm{dpi}$ after inoculation of chlamydiae (ANOVA, LSD, $\mathrm{p}<0.01$ ). In control animals neither a significant increase of FRC over time was seen nor a decrease of end-tidal $\mathrm{CO}_{2}$. End-tidal (i.e. alveolar) concentration of $\mathrm{CO}_{2}$ in exhaled breath decreased significantly from about $5 \mathrm{Vol} \%$ (baseline data in both groups) to 4.2 or $4.4 \mathrm{Vol} \%$, 
Table 2 Respiratory impedance assessed during expiration in the frequency range 3-15 $\mathrm{Hz}$ in calves either challenged with $10^{8}$ inclusion forming units of $C$. psittaci or sham-inoculated controls

\begin{tabular}{|c|c|c|c|c|c|c|c|}
\hline & & $-7 \mathrm{~d}$ a.i. & $-4 \mathrm{~d}$ a.i. & 3 dpi & $8 \mathrm{dpi}$ & $11 \mathrm{dpi}$ & $14 \mathrm{dpi}$ \\
\hline & & $n=18$ per group & $n=18$ per group & $\mathrm{n}=18$ per group & $\mathrm{n}=9$ per group & $\mathrm{n}=6$ per group & $\mathrm{n}=6$ per group \\
\hline \multirow[t]{4}{*}{ Xrs ex $3 \mathrm{~Hz}$} & C. psittaci & -0.018 & -0.021 & -0.038 & -0.040 & -0.018 & -0.010 \\
\hline & & {$[0.015]$} & {$[0.012]$} & {$[0.031]$} & {$[0.026]$} & {$[0.019]$} & {$[0.017]$} \\
\hline & Controls & -0.026 & -0.028 & -0.014 & -0.009 & 0.006 & 0.004 \\
\hline & & {$[0.026]$} & {$[0.028]$} & {$[0.017]$} & {$[0.019]$} & {$[0.015]$} & {$[0.011]$} \\
\hline \multirow[t]{4}{*}{ Xrs ex $5 \mathrm{~Hz}$} & C. psittaci & -0.003 & -0.009 & $-0.045 \downarrow$ & -0.034 & 0.000 & 0.007 \\
\hline & & {$[0.018]$} & {$[0.015]$} & {$[0.041]$} & {$[0.032]$} & {$[0.023]$} & {$[0.022]$} \\
\hline & Controls & -0.015 & -0.015 & 0.001 & -0.008 & 0.025 & 0.026 \\
\hline & & {$[0.035]$} & {$[0.032]$} & {$[0.021]$} & {$[0.025]$} & {$[0.022]$} & {$[0.020]$} \\
\hline \multirow[t]{4}{*}{ Xrs ex $10 \mathrm{~Hz}$} & C. psittaci & 0.041 & 0.027 & $-0.031 \downarrow$ & 0.005 & 0.045 & 0.047 \\
\hline & & {$[0.024]$} & {$[0.025]$} & {$[0.050]$} & {$[0.032]$} & {$[0.023]$} & {$[0.041]$} \\
\hline & Controls & 0.023 & 0.032 & 0.046 & 0.051 & 0.077 & 0.075 \\
\hline & & {$[0.045]$} & {$[0.038]$} & {$[0.031]$} & {$[0.033]$} & {$[0.033]$} & {$[0.032]$} \\
\hline \multirow[t]{4}{*}{ Xrs ex $15 \mathrm{~Hz}$} & C. psittaci & 0.058 & 0.049 & $0.002 \downarrow$ & 0.037 & 0.064 & 0.066 \\
\hline & & {$[0.028]$} & {$[0.026]$} & {$[0.046]$} & {$[0.023]$} & {$[0.018]$} & {$[0.035]$} \\
\hline & Controls & 0.047 & 0.050 & 0.068 & 0.067 & 0.089 & 0.093 \\
\hline & & {$[0.034]$} & {$[0.036]$} & {$[0.032]$} & {$[0.030]$} & {$[0.017]$} & {$[0.021]$} \\
\hline \multirow[t]{4}{*}{ Rrs ex $3 \mathrm{~Hz}$} & C. psittaci & 0.333 & 0.334 & 0.387 & 0.355 & 0.321 & 0.329 \\
\hline & & {$[0.051]$} & {$[0.038]$} & {$[0.103]$} & {$[0.059]$} & {$[0.052]$} & {$[0.074]$} \\
\hline & Controls & 0.335 & 0.339 & 0.314 & 0.303 & 0.284 & 0.279 \\
\hline & & {$[0.068]$} & {$[0.060]$} & {$[0.044]$} & {$[0.059]$} & {$[0.038]$} & {$[0.031]$} \\
\hline \multirow[t]{4}{*}{ Rrs ex $5 \mathrm{~Hz}$} & C. psittaci & 0.318 & 0.319 & 0.366 & 0.329 & 0.306 & 0.319 \\
\hline & & {$[0.047]$} & {$[0.036]$} & {$[0.096]$} & {$[0.046]$} & {$[0.048]$} & {$[0.071]$} \\
\hline & Controls & 0.337 & 0.318 & 0.300 & 0.291 & 0.276 & 0.272 \\
\hline & & {$[0.060]$} & {$[0.050]$} & {$[0.040]$} & {$[0.056]$} & {$[0.031]$} & {$[0.033]$} \\
\hline \multirow[t]{4}{*}{ Rrs ex $10 \mathrm{~Hz}$} & C. psittaci & 0.319 & 0.314 & 0.326 & 0.306 & 0.310 & 0.327 \\
\hline & & {$[0.042]$} & {$[0.031]$} & {$[0.079]$} & {$[0.038]$} & {$[0.035]$} & {$[0.061]$} \\
\hline & Controls & 0.328 & 0.314 & 0.302 & 0.302 & 0.299 & 0.296 \\
\hline & & {$[0.044]$} & {$[0.038]$} & {$[0.034]$} & {$[0.047]$} & {$[0.014]$} & {$[0.038]$} \\
\hline \multirow[t]{4}{*}{ Rrs ex $15 \mathrm{~Hz}$} & C. psittaci & 0.336 & 0.321 & 0.325 & 0.319 & 0.330 & 0.343 \\
\hline & & {$[0.041]$} & {$[0.027]$} & {$[0.074]$} & {$[0.043]$} & {$[0.040]$} & {$[0.055]$} \\
\hline & Controls & 0.344 & 0.339 & 0.327 & 0.324 & 0.335 & 0.324 \\
\hline & & {$[0.041]$} & {$[0.040]$} & {$[0.032]$} & {$[0.035]$} & {$[0.020]$} & {$[0.035]$} \\
\hline
\end{tabular}

d a.i., days ante inoculation; dpi, days post inoculation; Rrs ex, respiratory resistance during expiration; Xrs ex, respiratory reactance during expiration. Data are given as mean [standard deviation]. Significant difference between groups at the given time point are highlighted in bold (unpaired $t$-test, $\mathrm{p} \leq 0.05$ ). $\downarrow$ indicates a significant decrease compared to baseline data within one group (ANOVA, post hoc test: Bonferroni's multiple comparison procedure, $\mathrm{p} \leq 0.01$ ).

respectively, at 3-4 dpi in calves exposed to C. psittaci (Figure 6B).

\section{Blood gases and acid-base variables}

During the acute phase of infection and the development of respiratory illness, $\mathrm{pCO}_{2}$ in venous blood $\left(\mathrm{pCO}_{2}\right.$ (v) вт) of calves inoculated with $C$. psittaci was significantly reduced 2-3 dpi while blood $\mathrm{pH}$ was significantly increased 2 dpi compared to baseline values within the challenge group and compared to non-infected control calves at the same time points (Additional file 1). In the same time period, both $\mathrm{CHCO}_{3}^{-}$(st) and cBase (Ecf)) were significantly elevated $2 \mathrm{dpi}$ while all bicarbonate and base excess data $\left(\mathrm{cHCO}_{3}^{-}, \mathrm{cHCO}_{3}^{-}(\mathrm{st})\right.$, cBase, cBase (Ecf)) were significantly reduced one day later ( $3 \mathrm{dpi})$.

After a significant rise of $\mathrm{SIDm}_{3}$ at $1 \mathrm{dpi}$, all strong ion differences $\left(\mathrm{SIDm}_{3}, \mathrm{SIDm}_{4}, \mathrm{SIDm}_{5}\right)$ also dropped significantly down at 3 dpi compared to baseline data as well 
as compared to $\mathrm{SIDm}_{3}, \mathrm{SIDm}_{4}, \mathrm{SIDm}_{5}$ data assessed in controls (Additional file 2). Calculated anion gap (AG) was significantly elevated within the first 3 days after C. psittaci challenge while strong ion gap (SIG) was significantly reduced between 1-4 dpi (Additional file 1). The latter effect was more prominent in SIG (Alb) compared to SIG (Prt) due to significantly diminished $A_{\text {tot }}$ (Alb) values between 2-10 dpi compared to baseline data before challenge and compared to non-infected controls (Additional file 3). During the resolution period of clinical signs (about one week after inoculation), $\mathrm{pCO}_{2}(\mathrm{v})$ BT was significantly increased in C. psittaci infected calves compared to baseline data before challenge $(7 \mathrm{dpi}$, $10 \mathrm{dpi}$ ) and compared to data obtained from noninfected calves (7 dpi) without any marked changes in blood $\mathrm{pH}$. Within the period 7-10 dpi, $\mathrm{CHCO}_{3}^{-}, \mathrm{CHCO}_{3}^{-}$ (st), cBase, and cBase (Ecf) were significantly increased compared to baseline data and compared to data obtained from control calves (Additional file 1). $\mathrm{SIDm}_{3}$, $\mathrm{SIDm}_{4}$ and SIDm $_{5}$ started to increase significantly within the infected group at $7 \mathrm{dpi}$, and were even higher 10-14 dpi (significant in comparison to both baseline values and control calves) (Additional file 2). While the significant reduction in $\mathrm{A}_{\text {tot }}$ (Alb) lasted until $10 \mathrm{dpi}, \mathrm{A}_{\text {tot (Prt) }}$ was slightly increased $10-14 \mathrm{dpi}$ in calves exposed to the pathogen (Additional file 3). Thus, in comparison to non-infected calves, SIG (Prt) of calves exposed to C. psittaci was higher at $7 \mathrm{dpi}$ while SIG (Alb) was lower at 10 dpi (Additional file 1).

\section{Serum biochemical analysis and protein electrophoresis}

Blood concentration of inorganic phosphate of calves infected with $C$. psittaci decreased significantly between 1-10 dpi (compared to baseline data) with minima between 2-7 dpi that were also significantly lower than in controls (Additional file 3).

Serum albumin concentration was significantly reduced from 2 dpi till $10 \mathrm{dpi}$ in infected calves (compared to baseline values and compared to control calves) with a maximal reduction observed at 4-7 dpi. In contrast, concentration of serum globulins increased significantly over time after experimentally induced infection (different time courses of single globulin fractions as given in Additional file 3). Consequently, the concentration of serum proteins measured in calves infected with C. psittaci was, compared to baseline data, significantly decreased at 2-3 dpi and significantly increased at 10-14 dpi. The ratio between albumin and globulin in the infected group, however, was significantly decreasing in the course of the study (Additional file 3). 


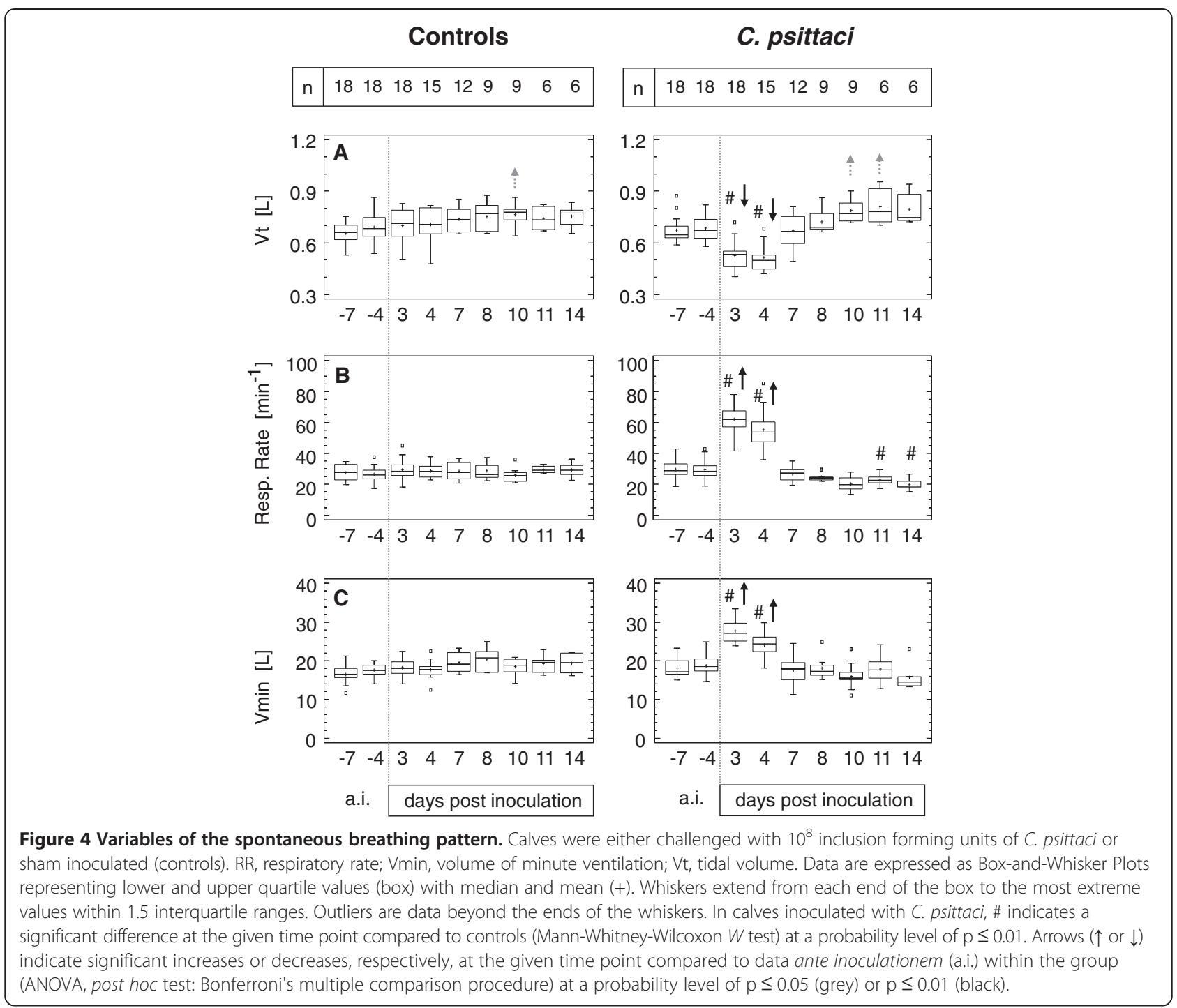

\section{cGlucose, cL-lactate and electrolytes}

Concentration of blood glucose was significantly reduced during the first 7 days after C. psittaci challenge with a lowest group median seen at 3 dpi. In contrast, cL-lactate in venous blood was significantly increased within the period 1-4 dpi with a highest group median seen at 2 dpi. Changes of cGlucose and cL-lactate in C. psittaci-inoculated calves were significant in comparison to both baseline data and control calves (Additional file 2). With respect to electrolytes in the peripheral blood, the concentrations of calcium, sodium, and chloride were slightly, but significantly, reduced in inoculated calves after challenge $\left(\mathrm{cCa}^{2+}: 2-4 \mathrm{dpi}, \mathrm{CNa}^{+}: 2-7 \mathrm{dpi}\right.$, $\mathrm{cCl}^{-}$: 2-14 dpi). Potassium concentration $\left(\mathrm{cK}^{+}\right)$was, compared to baseline values and compared to control calves, significantly increased at $1 \mathrm{dpi}$ and significantly decreased at 4 dpi after inoculation of C. psittaci (Additional file 2).

\section{Strong ion approach of acid-base disorders}

Figure 7 provides an example of the interplay of the aforementioned components during the acute phase (3 dpi) of the disease course. Decreases of $\mathrm{cNa}^{+}$and $\mathrm{cCl}^{-}$influenced $\mathrm{CHCO}_{3}^{-}$in an opposite manner. Similarly, the decrease of SID (acidotic effect) counterbalanced the decrease of $A_{\text {tot }}$, (alkalotic effect), thus effects of these parameters on blood $\mathrm{pH}$ (Additional file 1) appeared minimal.

\section{Discussion}

This prospective controlled study was undertaken to evaluate pulmonary dysfunctions induced by $C$. psittaci in the mammalian lung along with systemic acid-base alterations and imbalances in electrolytes and metabolites. A bovine model was exploited for the following reasons. (i) The lungs of species lacking collateral airways (predominantly cattle and pigs) are extremely sensitive to functional consequences of any changes in respiratory mechanics [37]. 


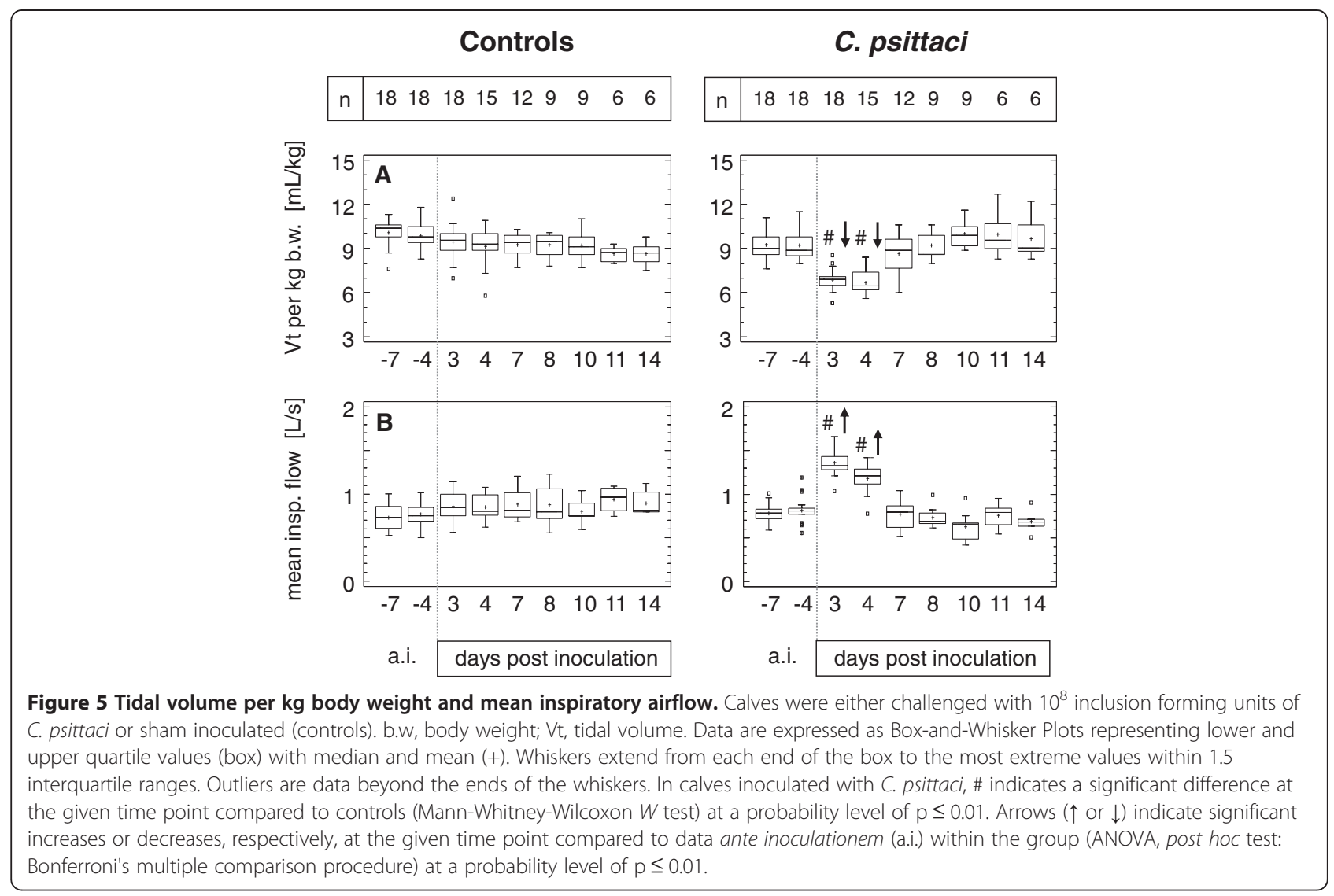

Thus, the bovine lung does present an advantageous model to assess pathophysiological consequences of both airway obstructions and pulmonary restrictions. (ii) This large animal model offers the great potential to perform non-invasively and almost painless long-term studies allowing a simultaneous within-subject approach of functional changes of both the organ and the systemic level.

In this particular model signs of acute respiratory illness were maximal 2-4 dpi and did not last longer than one week after challenge [38]. Although the severity of illness was mainly driven by respiratory signs, additional systemic reaction, similar to atypical pneumonias in human medicine [39] were observed. The most striking symptoms included dry cough, tachypnea, fever, reduced appetite, and tachycardia [38].

It was also shown earlier that in this model respiratory insufficiency during the acute phase $(2-3 \mathrm{dpi})$ is characterised by hypoxaemia, linked to reduced haemoglobin oxygen saturation, increased alveolar-arterial oxygen partial pressure difference and pulmonary shunt [40]. Due to long time course of the present study the risk of secondary infection after catheterising a representative arterial vessel was not taken, as anticipated advantages with respect to the evaluation of acid-base disorders and PFTs were thought to be minimal.

\section{Pulmonary dysfunctions}

Pulmonary function techniques from human medicine were applied to spontaneously breathing animals with body weights comparable to adult humans. Thus basic parameters of pulmonary functions (for example airflows and lung volumes) were more comparable and transferable to human patients compared to results obtained from murine models.

Furthermore, a functional differentiation between airway resistance and tissue mechanics of the lung was possible in the present study, while assessment of compliant properties of the lung in mice would require medical or surgical treatment $[41,42]$. During the acute period of illness (3-4 dpi) due to C. psittaci infection, the pattern of breathing was characterised by a significant decrease in tidal volume and a significant increase in both respiratory rate and airflows (clinically seen as short and rapid breathing cycles, i.e. dyspnoea). Per breath, dead space volume was significantly elevated while alveolar volume was reduced by about $10 \%$ indicating alveolar hypoventilation that was confirmed by a decreasing end-tidal concentration of $\mathrm{CO}_{2}$. However, global hypoventilation was not confirmed. In contrast, partial pressure of $\mathrm{CO}_{2}$ in peripheral blood decreased, too, indicating hypocapnia due to global hyperventilation. The latter was caused by an increase in 
Controls
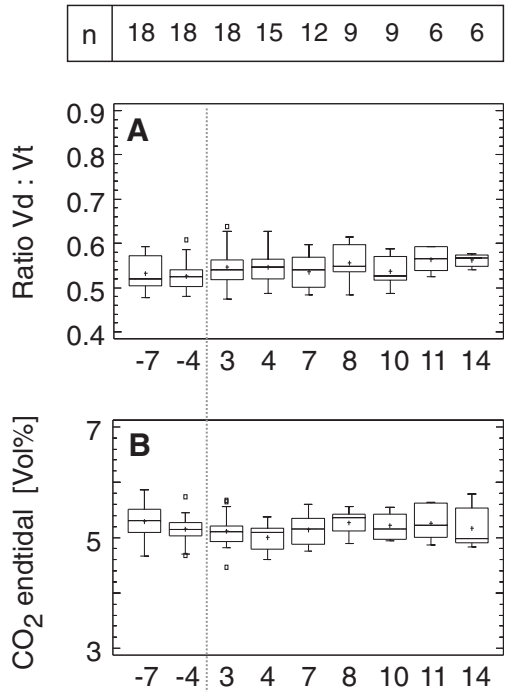

a.i.

days post inoculation

\section{C. psittaci}

$\mathrm{n} \quad 18 \begin{array}{llllllll}18 & 18 & 15 & 12 & 9 & 9 & 6 & 6\end{array}$
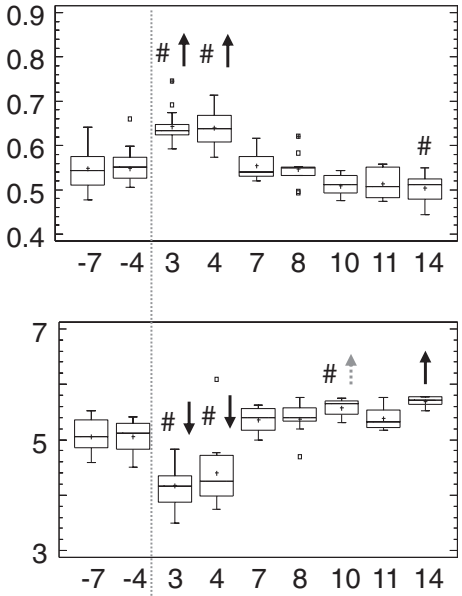

a.i.

days post inoculation

Figure 6 Dead space volume in relation to tidal volume and end tidal concentration of $\mathbf{C O}_{2}$. Calves were either challenged with $10^{8}$ inclusion forming units of C. psittaci or sham inoculated (controls). Vd, dead space volume; Vt, tidal volume. Data are expressed as Box-and-Whisker Plots representing lower and upper quartile values (box) with median and mean (+). Whiskers extend from each end of the box to the most extreme values within 1.5 interquartile ranges. Outliers are data beyond the ends of the whiskers. In calves inoculated with C. psittaci, \# indicates a significant difference at the given time point compared to controls (Mann-Whitney-Wilcoxon $W$ test) at a probability level of $p<0.01$. Arrows $(\uparrow$ or $\downarrow$ ) indicate significant increases or decreases, respectively, at the given time point compared to data ante inoculationem (a.i.) within the group (ANOVA, post hoc test: Bonferroni's multiple comparison procedure) at a probability level of $p \leq 0.05$ (grey) or $p \leq 0.01$ (black).

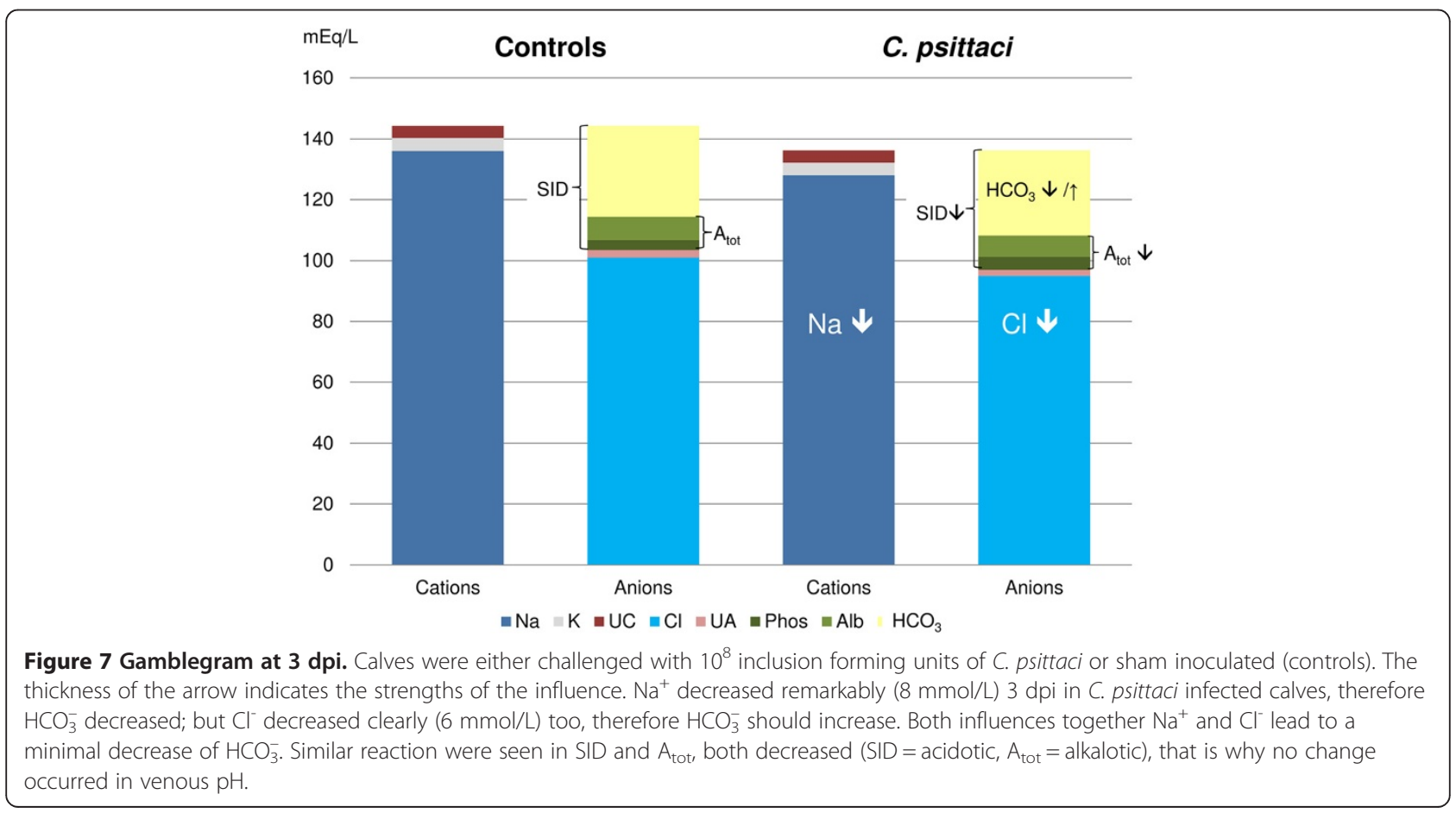


minute ventilation by $50 \%$ due to the strong increase in respiratory rate. The elevated minute ventilation was most likely the attempt to compensate for hypoxaemia induced by $C$. psittaci infection as shown previously [40].

Alterations in respiratory mechanics after inoculation of C. psittaci included both obstructive and restrictive components and lasted longer than the clinically visible changes in the pattern of respiration. Restriction was assessed by decreasing respiratory reactance (Xrs) which indicates limitations in elasticity or compliance of the lung-thorax system [23]. This loss in elasticity was predominantly a result of inflammatory reactions, such as cell infiltration, accumulations of fibrin and protein-rich fluid or signs of regeneration described for this model in detail elsewhere $[7,43]$. In the present study, the statistically significant decrease of Xrs at all frequencies (3-15 Hz) in C. psittaci challenged calves continued until 11 dpi. Thus, the duration of reduced compliant properties of lung tissue exceeded the presence of acute clinical signs [38] by about one week.

In the acute phase of respiratory illness, the loss of pulmonary compliance was most likely accompanied by stiffness of the peripheral respiratory system due to small airways narrowing or constriction [44]. Indeed, peripheral airflow was limited in calves inoculated with C. psittaci compared to control calves during the acute phase of disease which was indicated by an increase of Rrs $\leq 5 \mathrm{~Hz}$ and Rdist (significant at $3 \mathrm{dpi}$ and at 3-4 dpi, respectively). The negative frequency dependence of Rrs, i.e. an increase only at low frequencies $(\operatorname{Rrs}<5 \mathrm{~Hz})$, is a valid diagnostic tool to identify peripheral airways obstruction in both humans [45] and calves [21]. In addition to obstruction in distal airways, calves experimentally challenged with $C$. psittaci also suffered from obstruction in central or upper airways as indicated by an increase Rprox. These finding are in good agreement with reports in literature associating chlamydial infections in calves with both upper respiratory tract disease [3] and obstruction of peripheral airways [15]. Moreover, it was also shown in experimentally C. suis challenged pigs that peripheral airways obstruction during the acute phase ( $3 \mathrm{dpi}$ ) were followed by upper airways obstruction (at $7 \mathrm{dpi}$ ). To our knowledge lung function data of humans suffering from acute chlamydial pneumonia are not available, but taking these findings together obstruction of the upper and lower respiratory tract might probably also be involved in pathogenesis of acute chlamydial pneumonia in humans.

In parallel to the presence of airways obstruction, FRC increased significantly at 3-4 dpi. Baseline data of about $40 \mathrm{~mL} / \mathrm{kg}$ b.w. measured in this study in calves are in good agreement with data reported for the healthy bovine lung in adult cows $(38.6 \pm 3.1 \mathrm{~mL} / \mathrm{kg}$; [46]). After C. psittaci-infection, FRC increased significantly by $17 \%$ to $45.7 \mathrm{~mL} / \mathrm{kg}$ b.w. (3 dpi) which is moderate compared to FRC data reported in cows with severe bronchiolitis and an expanded lung field (56.5 $\pm 7.7 \mathrm{~mL} / \mathrm{kg}$; [47]). In calves, due to the lack of collateral airways, the presence of fibrin, inflammatory cells, detritus and protein rich fluid in the airways and/or alveoli during the acute phase of this model [43] resulted in narrowed peripheral airways which can easily result in the development of trapped air. In the present model the increase in FRC was transient, thus hyperinflation or over-distension of alveoli is indicated rather than the presence of emphysema [48]. As over-distension might reduce the recoil of elastic fibers it is likely that hyperinflation also contributed to reduced lung compliance described above. An increase of FRC was also reported for C. suis infected swine [49]. Radiographically-impressive distension of the lung with air is found in cases of C. trachomatis pneumonia in children, which despite the mild respiratory symptoms in infancy is associated with obstructive limitations up to 7-8 years after hospitalisation (i.e. increased FRC, forced and peak expiratory flow rates) [50,51]. A long-term impairment of lung function and structure after chlamydial infection was also shown for naturally Chlamydia-infected calves [15] and experimentally challenged mice [52]. In human medicine, asthma is a common chronic inflammatory disease of the airways, and the involvement of $C$. pneumoniae in asthma pathogenesis is still largely discussed $[53,54]$.

None of the lung functions assessed in control animals was significantly influenced by intrabronchial inoculation of BGM cell suspension. Pulmonary function data in control calves revealed physiological changes over time due to lung growth and development (gain in body weight during the study was $0.6 \mathrm{~kg}$ per day in average). In control calves Xrs increased significantly over time, displaying increasing compliant properties of lung and thorax. These findings are in line with fundamental understanding from the very beginning of veterinary pulmonology showing that lungs are easier to stretch with enhanced body or lung size $[55,56]$. It has been shown for growing calves that Xrs increased with increasing body weight [57]. During the period of pulmonary maturation (until a body weight of about $300 \mathrm{~kg}[58,59]$ ) bronchiolar diameters were also shown to increase [60], resulting in decreased airway resistance.

\section{Acid-base imbalances}

Compared to other studies [28,61-63] the control values of $\mathrm{pH}, \mathrm{pCO}_{2}, \mathrm{HCO}_{3}^{-}$, base excess and $\mathrm{A}_{\text {tot (Alb) }}$ or $\mathrm{A}_{\text {tot (Prt) }}$ are in the ranges reported whereas $\mathrm{AG}$ and $\mathrm{SIDm}_{3,4}$ were lower and SIG (Alb) or SIG (Prt) were higher in absolute values than those described in literature. In calves experimentally infected with C. psittaci, most of the effects assessed in venous blood were slight or moderate in 
amplitude and were mostly related to either the acute phase (2-4 dpi) or the resolution phase (7-10 dpi) after inoculation of the pathogen. Nevertheless the investigated parameters accurately assessed the influence of $C$. psittaci on the acid-base balance of the host organism.

Partial pressure of $\mathrm{CO}_{2}$ provides information regarding ventilation or respiratory component of acid-base balance in the Henderson-Hasselbalch equation as well as in the strong ion approach. Despite no access to arterial blood in this study, venous blood was informative enough identifying venous hypocapnia $\left(\mathrm{pCO}_{2}(\mathrm{v}) \downarrow\right) 2-3 \mathrm{dpi}$ as a result of hyperventilation (the latter was proved by pulmonary function testing). In general, hyperventilation can be caused primary by stimulation of pulmonary nociceptive receptors related to pulmonary disease and impairment of gas exchange (hypercapnia, hypoxaemia) or secondary for recovery from metabolic acidosis [64]. Natural compensatory mechanisms probably never overcompensate, and as a general rule, the $\mathrm{pH}$ will vary in a direction similar to the primary component disorder [65]. Therefore, it is more plausible that hyperventilation occurred to compensate for hypoxaemia, a known consequence of experimentally induced pulmonary disease in this model as reported previously by our group [40]. As a result, blood $\mathrm{pH}$ increased slightly 2 dpi. Decreases in both $\mathrm{cHCO}_{3}^{-}$and $\mathrm{CHCO}_{3}^{-}(\mathrm{st})$ at $3 \mathrm{dpi}$, together with decreased cBase and cBase (Ecf), can traditionally be interpreted as compensatory mechanisms to return to normal $\mathrm{pH}$. In the period 7-10 dpi, $\mathrm{cHCO}_{3}^{-}, \mathrm{cBase}$ and $\mathrm{cBase}$ (Ecf) increased but $\mathrm{pH}$ was not influenced. In conformity with the more modern approach, $\mathrm{cHCO}_{3}^{-}$, cBase and cBase (Ecf) are described as dependent (strong ion) variables that cannot be regulated independently of $\mathrm{pCO}_{2}$, while SID and $\mathrm{A}_{\text {tot }}$ are independent variables [66]. Only the independent variables influence the system and they are not influenced by the system. $A_{\text {tot }}$ and SID reflect the metabolic system. $A_{\text {tot (Alb) }}$ decreased 2-10 dpi and produced an alkalotic effect caused by hypo-albuminaemia. Albumin is a negative acute-phase protein, i.e. a marker of inflammation. This finding supplements our previously reported results identifying LBP (lipopolysaccharide binding protein) as a suitable marker of the acute phase in bovines $[38,40]$. In addition, albumin is the most important buffer in plasma [29]. $A_{\text {tot (Prt) was less affected }}$ because of hyper(gamma)globulinaemia, a spontaneous immune response. Our findings are in good agreement with data reported recently by Poudel et al. (2012) demonstrating that both the lowered plasma albumin and the increased globulin concentrations were associated with the intensity of $C$. pecorum infection in calves, and were attributed to ongoing systemic inflammation and its detrimental effects on liver function caused by chlamydiae [67].
$\mathrm{SIDm}_{3}, \mathrm{SIDm}_{4}$ and $\mathrm{SIDm}_{5}$ decreased 3 dpi (acidotic effect) caused by hyponatraemia (without change in haematocrit; data not shown) which dominated the concurrent hypochloraemia (alkalotic effect). $\mathrm{SIDm}_{3}, \mathrm{SIDm}_{4}$ and SIDm $_{5}$ increased slightly $10-14$ dpi due to continuing hypochloraemia and normalised sodium concentrations which led to a mild alkalotic effect as seen at the same time in a slightly increased $\mathrm{pH}$. Effects of increased potassium and lactate were compensated and were not seen in $\mathrm{SIDm}_{3}$. The adaptive retention of acid during sustained hypocapnia is normally accompanied by a loss of sodium into the urine [68]. To maintain the electroneutrality in blood in the presence of hyponatraemia, the $\mathrm{HCO}^{-}$concentration must decrease concurrently. The measured values of $\mathrm{cNa}^{+}$and base excess agree with studies by Funk (2007) [34], which showed that a decrease of sodium by $10 \mathrm{mmol} / \mathrm{L}$ explains a decrease of Base excess by $-3 \mathrm{mmol} / \mathrm{L}$.

This experimental study demonstrated again that often multiple acid-base disturbances exist concurrently and that mixed acid-base disturbances traditionally cannot be detected when the blood $\mathrm{pH}$ is unchanged. Strong ion theory provides evidence about the presence of acid-base imbalances, but only the selective view on the single parameters, which are required to calculate the strong ion variables, help to understand the complex response of the host organism and interactions between numerous variables.

\section{Conclusions}

The present study improved the current understanding of the pathophysiology of respiratory C. psittaci infections. Pulmonary dysfunctions and acid-base imbalances assessed by sensitive methods lasted clearly longer than clinically obvious signs and may thus also help elucidating functional host-pathogen interactions in the mammalian lung.

\section{Endnotes}

${ }^{a}$ Further analysis are based on calculations on $\mathrm{SIDm}_{3}$. However, to enable a better comparability to other studies $\mathrm{SIDm}_{4}$ and $\mathrm{SIDm}_{5}$ were additionally calculated:

$$
\begin{aligned}
& \operatorname{SIDm}_{4}[\mathrm{mmol} / \mathrm{L}]=\left(c \mathrm{Na}^{+}+c \mathrm{~K}^{+}\right)-\left(c \mathrm{Cl} \mathrm{l}^{-}+c L \text {-lactate }\right) \\
& \mathrm{SIDm}_{5}[\mathrm{mmol} / \mathrm{L}]=\left(c \mathrm{Na}^{+}+c \mathrm{~K}^{+}+c \mathrm{Ca}^{2+}\right)-\left(c \mathrm{Cl} l^{-}+c L \text {-lactate }\right) .
\end{aligned}
$$

Results are given in Additional file 2.

\section{Additional files}

Additional file 1: Results of blood-gas analysis, bicarbonate concentrations, base excess, anion gap, and strong ion gap. http:// respiratory-research.com/imedia/1164744271062177/supp1.xlsx. 
Additional file 2: Concentrations of plasma glucose, L-lactate, sodium, potassium, chloride, and calculated strong ion differences (SID). http://respiratory-research.com/imedia/1452059447106217/supp2.xlsx.

Additional file 3: Concentrations of inorganic phosphate and total protein, results of electrophoresis, and calculated values for $A_{\text {(tot). }}$. http://respiratory-research.com/imedia/5257028221062177/supp3.xlsx.

\section{Abbreviations}

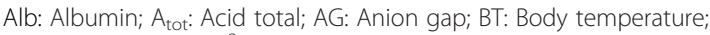
b.w.: Body weight; $\mathrm{Ca}^{2+}$ : Calcium; c: Concentration; cBase (Ecf): Standard base excess; cBase: Actual base excess; $\mathrm{Cl}^{-}$: Chloride; Cp: Chlamydia psittaci; dpi: Days post inoculation; FRC: Functional residual capacity; He: Helium; $\mathrm{HCO}_{3}{ }^{-}$: Bicarbonate; $\mathrm{HCO}_{3}{ }^{-}$(st): Standard bicarbonate; ifu: Inclusion forming units; $\mathrm{K}^{+}$: Potassium; $\mathrm{K}_{\mathrm{a}}$ : Acid dissociation constant; $\mathrm{Na}^{+}$: Sodium; m: Number of strong ions measured in plasma; p: Partial pressure; PFT: Pulmonary function tests; $\mathrm{pK}_{\mathrm{a}}:-\log { }_{10} \mathrm{~K}_{\mathrm{a}} ;$ Prt: Protein total; Rdist: Distal airway resistance; Rprox: Proximal airway resistance; RR: Respiratory rate; Rrs: Respiratory resistance; SD: Standard deviation; SID: Strong ion difference; SIG: Strong ion gap; Tex: Time of expiration; Tin: Time of inspiration; UA: Unmeasured anions; UC: Unmeasured cations; V: Venous; V'ex: Airflow (V') during expiration; V'in: Airflow (V') during inspiration; Vmin: Volume of minute ventilation; Vt: Tidal volume; Xrs: Respiratory reactance.

\section{Competing interests}

None of the authors of this paper has a financial or personal relationship with other people or organisations that could inappropriately influence or bias the content of the paper.

\section{Authors' contributions}

CO carried out pulmonary function tests, drafted parts of the manuscript. $S L$ analysed variables of acid-base status, performed statistical analysis of acid-base data, drafted parts of the manuscript. CSV participated in analysis of acid-base variables and drafted parts of the manuscript. PR conceived the study, and participated in its design and coordination, supported statistical analysis of lung function data, and revised the manuscript critically.

\section{Authors' information}

$\mathrm{CO}$ is PhD student at the Dahlem Research School, graduate school of 'Freie Universität Berlin'. SL is doctoral candidate at the Institute of Veterinary Physiology at the 'Freie Universität Berlin'. Both students will include parts of this manuscript in their theses. CO will focus on PFT data; SL will focus on acid-base data.

\section{Acknowledgements}

The authors are very grateful to Annelie Langenberg, Sylke Stahlberg, Ines Lemser, and all colleagues of the technical staff of the animal house for their excellent assistance while performing the in vivo phase of this study. In addition, they are thankful to all colleagues from the OIE Reference Laboratory for Chlamydiosis at Friedrich-Loeffler-Institut - particularly to Dr. Konrad Sachse, Dr. Evelyn Schubert, Dr. Anke Ruettger and Sabine Scharf for cultivation of chlamydiae and preparation of the challenge doses. Final language editing by Prof. Michael S. Davis (Oklahoma State University, USA) is very much appreciated.

Parts of the data were presented at the Congress of the European Respiratory Society, 1-5.09.2012, Vienna, Austria and at the $30^{\text {th }}$ Symposium of the Veterinary Comparative Respiratory Society, 22.-25.10.2012, Columbia, Missouri, USA.

\section{Financial disclosure}

This study was financially supported by the Federal Ministry of Education and Research (BMBF) of Germany under Grant no. 01 Kl 0720 "Zoonotic chlamydiae - Models of chronic and persistent infections in humans and animals". The funders had no role in study design, data collection and analysis, decision to publish, or preparation of the manuscript.

\section{Author details}

'Institute of Molecular Pathogenesis at 'Friedrich-Loeffler-Institut' (Federal Research Institute for Animal Health), Naumburger Str. 96a, 07743 Jena, Germany. ${ }^{2}$ Freie Universität Berlin, Faculty of Veterinary Medicine, Oertzenweg 19b, 14163 Berlin, Germany.
Received: 13 September 2013 Accepted: 18 December 2013

Published: 11 February 2014

\section{References}

1. Reinhold P, Sachse K, Kaltenboeck B: Chlamydiaceae in cattle: commensals, trigger organisms, or pathogens? Vet J 2011, 189:257-267.

2. Borel N, Thoma R, Spaeni P, Weilenmann R, Teankum K, Brugnera E, Zimmermann DR, Vaughan L, Pospischil A: Chlamydia-related abortions in cattle from Graubunden, Switzerland. Vet Pathol 2006, 43:702-708.

3. Twomey DF, Griffiths PC, Horigan MW, Hignett BC, Martin TP: An investigation into the role of Chlamydophila spp. in bovine upper respiratory tract disease. Vet J 2006, 171:574-576.

4. Kauffold J, Henning K, Bachmann R, Hotzel H, Melzer F: The prevalence of chlamydiae of bulls from six bull studs in Germany. Anim Reprod Sci 2007, 102:111-121.

5. Pantchev A, Sting R, Bauerfeind R, Tyczka J, Sachse K: Detection of all Chlamydophila and Chlamydia spp. of veterinary interest using species-specific real-time PCR assays. Comp Immunol Microb 2010, 33:473-484.

6. Kemmerling K, Müller U, Mielenz M, Sauerwein H: Chlamydophila species in dairy farms: polymerase chain reaction prevalence, disease association, and risk factors identified in a cross-sectional study in western Germany. J Dairy Sci 2009, 92:4347-4354.

7. Reinhold P, Ostermann C, Liebler-Tenorio E, Berndt A, Vogel A, Lambertz J, Rothe M, Rüttger A, Schubert E, Sachse K: A bovine model of respiratory Chlamydia psittaci infection: challenge dose titration. PloS One 2012, 7:e30125.

8. Ballard-Croft C, Wang DF, Sumpter $L R$, Zhou XQ, Zwischenberger JB: Large- Animal models of Acute Respiratory Distress Syndrome. Ann Thorac Surg 2012, 93:1331-1339.

9. Ireland JJ, Roberts RM, Palmer GH, Bauman DE, Bazer FW: A commentary on domestic animals as dual-purpose models that benefit agricultural and biomedical research. J Anim Sci 2008, 86:2797-2805.

10. Haas WH, Swaan CM, Meijer A, Neve G, Buchholz U, Beer M, van Steenbergen JE, Krause G: A Dutch case of atypical pneumonia after culling of H5N1 positive ducks in Bavaria was found infected with Chlamydophila psittaci. Euro Surveill 2007, 12, E071129.3.

11. Petrovay F, Balla E: Two fatal cases of psittacosis caused by Chlamydophila psittaci. J Med Microbiol 2008, 57:1296-1298.

12. Fraeyman A, Boel A, Van Vaerenbergh K, De Beenhouwer H: Atypical pneumonia due to Chlamydophila psittaci: 3 case reports and review of literature. Acta Clin Belg 2010, 65:192-196.

13. Theegarten D, Sachse K, Mentrup B, Fey K, Hotzel H, Anhenn O: Chlamydophila spp. infection in horses with recurrent airway obstruction: similarities to human chronic obstructive disease. Respir Res 2008, 9:14.

14. Theegarten D, Anhenn O, Hotzel H, Wagner M, Marra A, Stamatis G, Mogilevski G, Sachse K: A comparative ultrastructural and molecular biological study on Chlamydia psittaci infection in alpha-1 antitrypsin deficiency and non-alpha- 1 antitrypsin deficiency emphysema versus lung tissue of patients with hamartochondroma. BMC Infect Dis 2004, 4:38.

15. Jaeger J, Liebler-Tenorio E, Kirschvink N, Sachse K, Reinhold P: A clinically silent respiratory infection with Chlamydophila spp. in calves is associated with airway obstruction and pulmonary inflammation. Vet Res 2007, 38:711-728.

16. Stewart PA: Modern quantitative acid-base chemistry. Can J Physiol Pharmacol 1983, 61:1444-1461.

17. Constable PD: A simplified strong ion model for acid-base equilibria: application to horse plasma. J ApplPhysiol 1997, 83:297-311.

18. Bovarnick MR, Miller JC, Snyder JC: The influence of certain alts, amino acids, sugars, and proteins on the stability of rickettsiae. J Bacterio/ 1950, 59:509-522

19. Kneucker A, Langenberg A, Smith HJ, Reinhold P: Functional residual capacity and lung diffusion capacity in calves with chronic airflow obstruction caused by persistent chlamydial infection [abstract]. Eur Respir J 2008, 32(Suppl 52):4070.

20. Reinhold P, Reissig S, Jaeger J, Langenberg A, Smith HJ: Capnovolumetry is a useful technique to detect peripheral airway obstruction [abstract]. Eur Respir J 2007, 58(Suppl 51):233. 
21. Reinhold P, Smith HJ, Close R, Genicot B, Lekeux P: Validation of impulse oscillometry in Friesian and Blue Belgian calves with respect to changes in extrathoracic upper airway resistance. Res Vet Sci 1998, 65:93-101.

22. Reinhold P, Smith HJ, Langenberg A, Lekeux P: Measurement of respiratory impedance in healthy calves using the impulse oscillation technique - Physiological and methodological aspects. Vet J 1998, 155:27-38.

23. Smith H, Reinhold P, Goldman M: Forced oscillation technique and impulse oscillometry. Eur Respir Mon 2005, 31:72-105.

24. Oh MS, Carroll HJ: The anion gap. New Engl J Med 1977, 297:814-817.

25. Constable PD, Hinchcliff KW, Muir WW 3rd: Comparison of anion gap and strong ion gap as predictors of unmeasured strong ion concentration in plasma and serum from horses. Am J Vet Res 1998, 59:881-887

26. Constable PD: Clinical assessment of acid-base status: comparison of the Henderson-Hasselbalch and strong ion approaches. Vet Clin Pathol 2000, 29:115-128.

27. Reinhold P, Hartmann H, Constable PD: Characterisation of acid-base abnormalities in pigs experimentally infected with Chlamydia suis. Vet $J$ 2010, 184:212-218.

28. Constable PD, Stämpfli HR, Navetat H, Berchtold J, Schelcher F: Use of a quantitative strong ion approach to determine the mechanism for acid-base abnormalities in sick calves with or without diarrhea. J Vet Intern Med 2005, 19:581-589.

29. Constable PD, Stämpfli HR: Experimental determination of net protein charge and $\mathrm{A}(\mathrm{tot})$ and $\mathrm{K}(\mathrm{a})$ of nonvolatile buffers in canine plasma. J Vet Intern Med 2005, 19:507-514.

30. Kellum JA, Kramer DJ, Pinsky MR: Strong ion gap: a methodology for exploring unexplained anions. J Crit Care 1995, 10:51-55.

31. Reeves RB: Temperature-induced changes in blood acid-base status: $\mathrm{pH}$ and PCO2 in a binary buffer. J Appl Physiol 1976, 40:752-761.

32. de Morais HSA: A nontraditional approach to acid-base disorders. In Fluid Therapy in Small Animal Practice. Edited by DiBartola SP. Philadelphia: Saunders (W.B.); 1992:297-320.

33. Whitehair KJ, Haskins SC, Whitehair JG, Pascoe PJ: Clinical applications of quantitative acid-base chemistry. J Vet Intern Med 1995, 9:1-11.

34. Funk GC: [Stewart's acid-base approach] german. Wien Klin Wochenschr 2007, 119:390-403.

35. Gibbons JD: Nonparametric Statistical Inference. 2nd edition. New York and Basel: Marcel Dekker, Inc.; 1985.

36. Hollander M, Wolfe DA: Nonparametric Statistical Methods. New YorkSydney-Tokyo-Mexico City: John Wiley \& Sons; 1973.

37. Kirschvink N, Reinhold P: Use of alternative animals as asthma models. Curr Drug Targets 2008, 9:470-484.

38. Ostermann C, Rüttger A, Schubert E, Schrodl W, Sachse K, Reinhold P: Infection, disease, and transmission dynamics in calves after experimental and natural challenge with a bovine Chlamydia psittaci isolate. PloS One 2013, 8(5):e64066.

39. Cunha BA: The atypical pneumonias: clinical diagnosis and importance. Clin Microbiol Infect 2006, 12(Suppl 3):12-24.

40. Ostermann C, Schroedl W, Schubert E, Sachse K, Reinhold P: Dose-dependent effects of Chlamydia psittaci infection on pulmonary gas exchange, innate immunity and acute-phase reaction in a bovine respiratory model. Vet $J$ 2013, 196:351-359.

41. Glaab T, Taube C, Braun A, Mitzner W: Invasive and noninvasive methods for studying pulmonary function in mice. Respir Res 2007, 8:63.

42. Hoymann HG: Lung function measurements in rodents in safety pharmacology studies. Front Pharmacol 2012, 3:156.

43. Lambertz J: [Pathology and pathogenesis of an experimental aerogenous infection of calves with Chlamydophila psittaci (non-avian origin)], Thesis (german). Tierärztliche Hochschule Hannover; 2011. http://elib.tihohannover.de/dissertations/lambertzj_ss11.pdf.

44. Reinhold P, Langenberg A, Lekeux P: [Review of respiratory mechanics in animals. 4. The diagnostic affirmation ability of research using the impulse oscilloresistometry system (IOS) in calves] german. Berl Münch Tierärztl Wochenschr; 1998:262-267.

45. Short PM, Williamson PA, Lipworth BJ: Sensitivity of impulse oscillometry and spirometry in beta-blocker induced bronchoconstriction and beta-agonist bronchodilatation in asthma. Ann Allergy Asthma Immunol 2012, 109:412-415.
46. Gallivan GJ, Mcdonell WN: An evaluation of the Multiple-Breath Nitrogen Washout as a Pulmonary-Function Test in dairy-cattle. Can J Vet Res 1989, 53:133-142.

47. Gallivan GJ, Viel L, Baird JD, Mcdonell WN: Pulmonary structure and function in adult dairy-cows with an expanded lung field. Can J Vet Res 1991, 55:15-20.

48. Caswett J, Williams K: Respiratory System. In Jubb, Kennedy \& Palmer's Pathology of Domestic Animals, Volume 2. 5th edition. Edited by Maxie MG. London, UK: Elsevier; 2007:523-653.

49. Reinhold P, Kirschvink N, Theegarten D, Berndt A: An experimentally induced Chlamydia suis infection in pigs results in severe lung function disorders and pulmonary inflammation. Vet Res 2008, 39:35.

50. Weiss SG, Newcomb RW, Beem MO: Pulmonary assessment of children after Chlamydial Pneumonia of infancy. J Pediatr 1986, 108:659-664.

51. Horwitz AE: [Imaging methods in airway and lung diseases of children - conventional diagnostics] german. Atemw-Lungenkrkh 2010, 36:266-279.

52. Jupelli M, Murthy AK, Chaganty BKR, Guentzel MN, Selby DM, Vasquez MM, Mustafa SB, Henson BM, Seidner SR, Zhong GM, Arulanandam BP: Neonatal chlamydial pneumonia induces altered respiratory structure and function lasting into adult life. Lab Invest 2011, 91:1530-1539.

53. Metz G, Kraft M: Effects of atypical infections with Mycoplasma and Chlamydia on asthma. Immunol Allergy Clin North Am 2010, 30:575-585. vii-viii.

54. Papadopoulos NG, Christodoulou I, Rohde G, Agache I, Almqvist C, Bruno A, Bonini S, Bont L, Bossios A, Bousquet J, Braido F, Brusselle G, Canonica GW, Carlsen KH, Chanez P, Fokkens WJ, Garcia-Garcia M, Gjomarkaj M, Haahtela T, Holgate ST, Johnston SL, Konstantinou G, Kowalski M, Lewandowska-Polak A, Lødrup-Carlsen K, Mäkelä M, Malkusova I, Mullol J, Nieto A, Eller $E$, et al: Viruses and bacteria in acute asthma exacerbations-a GA(2) LEN-DARE systematic review. Allergy 2011, 66:458-468.

55. Mercer RR, Russell ML, Crapo JD: Alveolar septal structure in different species. J Appl Physiol 1994, 77:1060-1066.

56. Spörri $H$, Zerobin $K$ : [About the physiology and methodology of pulmonary function tests] german. Tierärztl Umschau 1964, 19:285-292.

57. Reinhold P, Steinbach G, Langenberg A, Lekeux P: [Review of respiratory mechanics in animals. 3. Methodical and physiologic aspects of the use of the impulse oscilloresistometry system (IOS)] german. Berl Münch Tierärztl Wochenschr 1998, 111:253-261.

58. Lekeux P, Hajer R, Breukink HJ: Effect of somatic growth on pulmonary-function values in healthy friesiancattle. Am J Vet Res 1984, 45:2003-2007.

59. Gustin P, Bakima M, Art T, Lekeux P, Lomba F, van de Woestijne KP: Pulmonary function values and growth in Belgian white and blue double-muscled cattle. Res Vet Sci 1988, 45:405-410.

60. Castleman WL, Lay JC: Morphometric and ultrastructural-study of postnatal lung growth and development in calves. Am J Vet Res 1990, 51:789-795.

61. Bachmann L: [Suitability of the Stewart variables of acid-base status in the analysis of processes in the abomasum and blood of calves on differing diets], Thesis (german). Berlin: Freie Universität Berlin; 2008. http://www.diss.fu-berlin.de/diss/servlets/MCRFileNodeServlet/ FUDISS_derivate_000000004071/bachm.pdf?hosts.

62. Constable PD: Calculation of variables describing plasma nonvolatile weak acids for use in the strong ion approach to acid-base balance in cattle. Am J Vet Res 2002, 63:482-490.

63. Elkhair NM, Siegling-Vlitakis C, Radtke E, Willing A, Hartmann H: Age-dependent response of the acid-base parameters (Henderson-Hasselbalch, Stewart) in healthy calves with experimentally induced metabolic acidosis. Berl Münch Tierärztl Wochenschr 2009, 122:63-69.

64. Wall RE: Respiratory acid-base disorders. Vet Clin North Am Small Anim Pract 2001, 31:1355-1367. viii.

65. Haskins SC: An overview of acid-base physiology. J American Vet Med Assoc 1977, 170:423-428.

66. Kellum JA: Determinants of blood $\mathrm{pH}$ in health and disease. Crit Care 2000, 4:6-14. 
67. Poudel A, Elsasser TH, Rahman KS, Chowdhury EU, Kaltenboeck B:

Asymptomatic endemic Chlamydia pecorum infections reduce growth rates in calves by up to 48 percent. PLoS One 2012, 7(9):e44961.

68. Madias NE, Adrogue HJ: Cross-talk between two organs: how the kidney responds to disruption of acid-base balance by the lung. Nephron Physiol 2003, 93:61-66.

doi:10.1186/2049-6958-9-10

Cite this article as: Ostermann et al.: Evaluation of pulmonary dysfunctions and acid-base imbalances induced by Chlamydia psittaci

in a bovine model of respiratory infection. Multidisciplinary Respiratory Medicine 2014 9:10.

\section{Submit your next manuscript to BioMed Central and take full advantage of:}

- Convenient online submission

- Thorough peer review

- No space constraints or color figure charges

- Immediate publication on acceptance

- Inclusion in PubMed, CAS, Scopus and Google Scholar

- Research which is freely available for redistribution 